\title{
A Perspective on Disability and Rehabilitation
}

\begin{abstract}
This paper is written in honor of the memory of the late Jules Rothstein, editor in chief "emeritus" of the Physical Therapy (the journal of the American Physical Therapy Association - APTA) who passed away on the 27-08-2005. It is fitting to dedicate a paper on disability to Dr. Rothstein, as he himself likened disability with the identity of physiotherapy. A paper focusing on disability at this time might be the wake up call needed to make physiotherapists heed the African decade of the disabled person, which is more than halfway through. The paper highlights the problem of sparse evidence in rehabilitation and emphasizes the need for an evidence-based approach to rehabilitation. Practical suggestions for the implementation of EBP in rehabilitation using the International Classification of Functioning, Disability (ICF) as a framework are proposed. This paper is envisaged to enthuse rehabilitation physiotherapists to embrace EBP, so that their focus is redirected to the 'eradication of disability'.
\end{abstract}

\section{KEY WORDS: EVIDENCE BASED PRACTICE, REHABILITATION; DISABILITY, ICF.}

\section{INTRODUCTION}

I met Jules Rothstein on two occasions only. The first time I was in Reykjavik, Iceland in June 2000 at the Nordic research symposium on 'Evidence Based Practice - bridging the research practice gap'. He was one of the keynote speakers and also conducted a practical workshop on EBP. Commencing a very fruitful and educational workshop, he stated that "...if EBP was a child, physiotherapist would be arrested for abuse". That seized my attention for the entire workshop, and since then I have been "sold" on EBP and have followed Jules' papers in the APTA journal. As a rehabilitation therapist, I was captivated by his thought provoking editorials, his writings of measurements in science, and his passion for disability. My second encounter with Jules was the 2003 congress of the World Confederation for Physical Therapy in Barcelona. From these two encounters and from reading his work, Jules left an impression on me as a rehabilitation therapist that says ' $g o$ back to your roots-focus on disability and have an evidence based approach to rehabili-

CORRESPONDENCE TO: Joyce Mothabeng University of Pretoria Tel: (012) 354-1200

Fax: (012) 354-1226

Email: joyce.mothabeng@up.ac.za tation". Hence, this paper on disability and rehabilitation is dedicated to him.

\section{BACKGROUND}

Disability is a global phenomenon eliciting local, national and international concern. The population of physically disabled people in the world is on the increase because of violence, trauma, lifestyle diseases and other causes. According to two national surveys, over five percent of the South African population is severely disabled (Case Disability survey 2001, Statistics South Africa 2005).

In recognition of the rights and needs of persons with disabilities the African Union, declared the African decade of persons with disabilities, from 1999-2009.

With disability being high on the African agenda, it needs to be given priority by all health professionals, including physiotherapists. As rehabilitation professionals involved in the prevention, treatment and overall management of disability, physiotherapists have a responsibility to ensure that the African decade successfully achieves the goals set out. We need to engage in research activity that will enhance the quality of life of disabled persons. As Africa enters into the second half of the Decade for Persons with Disabilities, we need to reflect on our profession's contribution to improving quality of life for people with disabili- ties. The goal of the African Decade for persons with disabilities is the full participation, equality, and empowerment of people with disabilities in Africa.

\section{THE NEED FOR DISABILITY RELATED RESEARCH IN PHYSIOTHERAPY}

Physical disability is one category of disability that is a direct beneficiary of physiotherapy services. The prevalence of Disability in South Africa was reported to be $13 \%$ in 1995 , with $5 \%$ of those being severely disabled. Physiotherapy and other Health professions need to respond to the needs of these people. This is imperative because Disability has been earmarked a national issue in South Africa, in keeping with the transformation of the country (OSDP 1997). Physiotherapists and other members of the health care team need to engage in research activities to enhance the quality of life of disabled people.

In their article entitled 'Disability Research in South Africa', Bhagwanjee and Stewart (1999) raised concern about the paucity of healthcare literature on Disability issues in South Africa. Disability research is needed in Africa as a whole; and South Africa specifically, where the vicious cycle of HIV/AIDS, violence, wars and poverty leads to disability, which causes further poverty, and the cycle continues. The lack of resources and the inadequate allocation of health budgets fuel the situation even more. 
The global need for Evidence based rehabilitation and rehabilitation research was highlighted in April 2005 at a rehabilitation research summit of USA rehabilitation professionals (Fronterra and Wade 2006). The summit identified the need for the following regarding rehabilitation research:

- continuous work to enhance the science of rehabilitation,

- improvement in the methods of studying rehabilitation,

- training new investigators in this area, and

- advocacy for this important research

\section{REHABILITATION RESEARCH}

Rehabilitation research lags behind medicine (e.g. drug development and many surgical fields) and nursing research as far as the ability to demonstrate the effectiveness of interventions is concerned (Dromerick 2003). Drug development requires at least one multicentre randomized controlled trial (RCT) before legal approval can be obtained, and in surgery, many of the procedures are tested through RCT's (op cit).

Dromerick (2003) identified the following as reasons why rehabilitation is 'susceptible to the acceptance of treatments with little or no direct evidence of efficacy':

- The lack of obvious and catastrophic clinical failure to force rehabilitationists to test and refine ideas and treatments... patients do not obviously and immediately die from bad rehabilitation, as they might from poor surgical techniques or ineffective drugs. Thus, rehabilitationists do not face the same discipline of clinical failure that many other clinicians face.

- Treatment often has no hard end points. Since rehabilitationists strive to promote independence, quality of life, and other difficult-to-measure goals....., how do we measure what we claim to be improving?

- the nature of most rehabilitation interventions makes standardizing the treatment intervention difficult; a behavioral treatment such as a motor therapy or a memory-retraining strategy is much more operatordependent than simply giving the patient a drug or device.

- Finally, rehabilitation lacks the type of industry interest that drives the development of new drugs and devices.

\section{EVIDENCE BASED REHABILITATION}

We are living in times where change is a constant feature at every level of society and health-care delivery is no exception. Rehabilitation professionals today are facing many challenges because of rapid changes in society. One of these is the fact that we have to become more accountable to society and to our patients.

(Grant 1998). Gone are the days when it was assumed that as professionals we know best what to do, and how to do it. We are now living in times where we need to show with scientific evidence that we are the best at what we do; and that it works. But what is evidencebased practice?

$E B P$ is the conscientious, explicit and judicious use of current best evidence to make decisions about patient care and other professional practice issues (e.g. education, management etc) (Sacket 1996)

In the context of rehabilitation, EBP can be described as the process by which professionals make rehabilitation decisions using the best available research evidence, their clinical expertise and patient preferences (Bury and Mead 1998).

Every encounter we make with a patient should elicit questions regarding our knowledge about the etiology, diagnosis, prognosis, or therapy of their illness, thus identifying knowledge gaps. Even the most seasoned practitioners generate knowledge "needs" with every patient they encounter. By adopting an evidence-based approach to rehabilitation, we can address these needs and provide the best rehabilitation for our patients. EBP is thus vital to the rehabilitation therapist mainly for three main reasons:

\section{Decision-making}

Rehabilitation professionals make many patient management decisions on a daily basis. Such decisions can be relatively inconsequential, while others are vitally important. It is therefore important that a combination of evidence, values and resources be considered when making such decisions. Unfortunately most rehabilitation decisions tend to be based on opinion and/or experience; and rarely if ever on evidence. (Bury and Mead 1998).

\section{To prove the effectiveness of our interventions}

We engage in a lot of opinion-based practice, instead of evidence-based practice. A common physiotherapy saying is "It works!" Some practices are religiously followed because they have been found to be effective "from experience" or it was "the advice of some expert." Are we now into "experience based practice" "expert based practice" or what? (Sacket 1996). Our survival and credibility as a profession are at risk if we are unable to demonstrate that our treatments and/or approaches have a significant beneficial effect on our people with disabilities and that they are cost effective.

Although the physiotherapy profession has come a long way towards developing a credible knowledge base in general (Calhan 1988), there is a need for disability and rehabilitation research to be made a priority in the profession (Johnston et al, 2006). High level evidence needs to be generated for rehabilitation techniques being used by therapists. This need has been acknowledged in the National Rehabilitation Strategy (DOH 2001) and the SASP Rehabilitation Document (SASP 2004). Two recent reviews on neurorehabilitation highlighted the need for 'level one evidence' to be generated to support the use of a fairly new technique, Constraint Induced Movement Therapy (Herbert et al 2001, Wade and Barrel 2006).

\section{To Justify our existence}

Bowerbank (1997) once posed the following thought-provoking questions to South African Physiotherapist:

- Why do we exist

- Will we continue to exist

- In what shape and form will we exist?

As a profession, we have to find ways of making an impact in communities where we are needed otherwise our services will not be sought after (Eales S, 2001) and we will have no reason to exist! We need to acknowledge the paradox of success that "what got us where we are, won't keep us where we are" (Grant 1997). We must keep questioning; and striving for excellence in these times of change. 


\begin{tabular}{|l|l|l|l|l|}
\hline ICF & \multicolumn{2}{|l|}{ Part 1: Functioning and Disability } & \multicolumn{2}{l|}{ Part 2: Contextual Factors } \\
\hline Components & $\begin{array}{l}\text { Body functions } \\
\text { and Structures }\end{array}$ & $\begin{array}{l}\text { Activities and } \\
\text { Participation }\end{array}$ & $\begin{array}{l}\text { Environmental } \\
\text { factors }\end{array}$ & Personal Factors \\
\hline Domains & $\begin{array}{l}\text { Body functions } \\
\text { and Structures }\end{array}$ & $\begin{array}{l}\text { Life areas } \\
\text { (tasks, actions) }\end{array}$ & $\begin{array}{l}\text { External influences } \\
\text { on functioning and } \\
\text { disability }\end{array}$ & $\begin{array}{l}\text { Internal influences } \\
\text { on functioning and } \\
\text { disability }\end{array}$ \\
\hline
\end{tabular}

(Source World Health Organisation 2001)

We also need to be able to defend a strong and coherent professional profile within the current reforms of healthcare. This can only be achieved through EBP, which in turn is grounded in appropriate and valid research. If an EBP approach is not used - we will lose credibility with our clients, funders, policy makers and he rest of he healthcare fraternity. Only through adopting an evidence-based approach to rehabilitation and actively engaging in generating the rehabilitation evidence can we ensure our relevance and continued existence. EBP suitable within an African context needs to be grounded in research that is relevant to South Africa in particular and Africa in general.

\section{HOW CAN WE MAKE REHABILITATION EVIDENCE BASED?}

There are there steps to EBP according to Culham (1998). These include knowledge generation through research, knowledge transmission through education and/or publication and knowledge application. This section will focus on knowledge generation and application. The discussion on knowledge transmission will be covered in another publication that focuses on disability research publications in physiotherapy (Mothabeng 2006)

\section{Knowledge generation}

Physiotherapy research efforts must endeavor to address issues pertinent to the South African community. We risk being labeled an irrelevant profession if we are not going to address priority health issues of the country, which include disability. The National Health Bill (2001) states that health research must be directed at promoting health; preventing disease and disability and curing disease.

The World Health Organization has provided the International Classification of Functioning, Disabilities and Health (table 1) as a framework to help healthcare worker understand consequences of ill health or injury (Bornman 2004). The ICF is a framework and classification system for use in describing functioning and disability in relation to a health condition. The ICF differentiates three levels of injury/ill health outcomes: the organ level, personal level and social level (WHO 2001). Physiotherapists are concerned with the functional status of patients at all three levels and the aim of physiotherapy interventions is to maintain or improve current level of functioning or to prevent deterioration. Physiotherapists therefore need to be cognisant with this framework, and apply it in rehabilitation research. Framing rehabilitation research within the ICF will allow us to study the impact of disability on all three levels, thus generating various forms of evidence.

Research at the body structure and function level will address issues related to impairment evaluation and management. One of the biggest challenges facing rehabilitation therapists is spasticity. How do we measure and manage it? Are the methods effective? The questions are endless, and need to be researched (Thompson et al. 2005).

At the level of personal function, we can address various issues related to function using various appropriately developed outcome measures. Outcome measures are essential for the evaluation and management of rehabilitation (Haigh et al 2001). Some measures have not been proved valid or reliable. Others are valid and reliable but not necessarily culturally sensitive to the context in which they are used. Research is therefore needed to establish the relevance and evidence of these measures.

The ultimate outcome of rehabilitation is measured at the level of society, whether our patient are functioning as independent members and fully rein tegrated into their communities. Rehabilitation research at this level should look into issues influencing participation in society and how this participation can be facilitated.

\section{CONCLUSION}

The African continent is faced up with unique problems of huge populations, limited number of therapists, huge demands for rehabilitation services and limited resources. The rehabilitation challenges are therefore unique. Rehabilitation professionals need to advance their understanding of Disabilities and related problems through research. The physiotherapy profession has its origins in the remediation of disability, "where we endeavor to bring meaningful function back into the lives of those who seek our services' (Rothstein 1994). That is our identity and we should not be distracted from it. We need to develop this identity by making sure that our rehabilitation efforts do address disability and are based on evidence.

\section{REFERENCES}

Bhagwanjee AM, Steward R 1999. Disability research in South Africa: Vision and imperatives for a national coordinated approach. South African Journal of Occupational Therapy 29:15-17

Bornman J 2004 The World Heath Organization's terminology and classification: applications to severe disability. Disability and Rehabilitation 26 (3) 182-188.

Bowerbank P 1997 Physiotherapy: Four models of survival. Paper presented at the SASP International congress held in Cape Town, 31 March to 3 April

Bury T, Mead J. 1998.Evidence-based healthcare: a practical guide for therapists. Oxford: Butterworth-Heinemann)

Culham E 1998 Evidence Based Practise and professional credibility. Physiotherapy Theory and Practice (1998) 14. 65-67

Dromerick AW 2003 Evidence-based rehabilitation: the case for and against constraint-induced movement therapy. Journal of Rehabilitation Research Development, 40:vii-ix

Eales CJ 2000: Editorial - Change: 'Make or become different' or simply making a difference. Physiotherapy Research International $5(2) 3-4$

Fronterra WR, Ward SR 2006 Prologue to 'Rehabilitation medicine summit: building research capacity - Executive summary'. Physical Therapy 86: 282-284 